\title{
М.Ц. Гончикова
}

\section{ТРАДИЦИИ БУРЯТСКОЙ НАРОДНОЙ МУЗЫКИ КАК ОСНОВА ФОРМИРОВАНИЯ ПРОФЕССИОНАЛЬНОЙ МУЗЫКАЛЬНОЙ КУЛЬТУРЫ И ОБРАЗОВАНИЯ В РЕСПУБЛИКЕ БУРЯТИЯ}

\footnotetext{
В статье рассмотрены жанровые особенности музыкального фольклора бурят, составившие основу профессиональной музыкальной культуры и образования: музыкально-поэтический эпос (улигеры), народные песни и инструментальная музыка. Актуальность рассматриваемой проблемы определяется региональным фактором, состоящим в необходимости сохранения, приумножения и восстановления культурных и художественных традиций Бурятии, сформировавиихся на протяжении длительного исторического периода.

Ключевые слова: музыкальная культура, образование, традиции, фольклор.
}

Буряты, как и многие народы нашей страны, с древнейших времен располагали богатой, только им присущей духовной культурой. Она являлась результатом их длительного развития, шла в русле мировой цивилизации и в то же время имела характерные специфические приоритетные национальные ценности и особенности.

Историческую основу культуры бурят составляет комплекс материальных и духовных ценностей, относящихся в целом к культуре монгольского этноса. Народы Центральной Азии с древнейших времен на протяжении многих веков являлись участниками единого процесса эволюции общества. Общность культур народов Центральной Азии на разных этапах истории проявляется в определенных аспектах материального и духовного творчества в отдельных регионах: в предметах быта, традиционных обрядах, архитектуpe, музыке, музыкальных инструментах, орнаменте одежды и т. д.

K XVII в. сформировалось несколько монголоязычных групп, крупнейшими из которых были эхириты, булагаты, хори и хонгодоры. После присоединения к России и установления государственной границы с Китаем и Монголией произошло объединение разрозненных монголоязычных групп, проживающих на территории Байкальского региона - Предбайкалья и Забайкалья. Образование бурятской народности было обусловлено этническим родством, сходством духовной и материальной культур, близостью языка, а также социально-политическим объединением бурятских племен и родов после вхождения в состав России.

Следует отметить, что геополитическое положение Бурятии обусловило особое ее развитие в политической, экономической и культурной областях. Традиции музыкальной культуры бурят развивались в условиях воздействия и влияния двух систем культуры и идеологии - западной (христианской) и восточной (буддийской).

Народное музыкальное творчество - уникальное явление художественной культуры социума. Оно отражает национальное художественное сознание 
и менталитет того или иного народа, в нем закрепляются эстетические ценности народа. Это «коллективная творческая деятельность трудового народа, выражающая его жизнь, воззрения, идеалы, создаваемые народом и бытующие в народных массах поэзия (предания, песни, сказки, эпос), музыка (песни, сказки, наигрыши, пьесы), театр (драмы, сатирические пьесы), танец, архитектура, изобразительное искусство и декоративно-прикладное искусство» [1. С. 620].

Народная музыка как неотъемлемая область фольклора интегрирует культуру социума определенной этнической принадлежности на особом витке исторического развития общества, воплощает высшие духовные силы народа и отражает элементы национального художественного сознания. Поэтому народное музыкальное творчество любого народа основано на единых принципах и законах развития фольклора, характерными особенностями которого являются коллективность творческого процесса, изустность передачи, синкретизм, вариативность, импровизационность, бифункциональность и полиэлементность, локальность и др.

Безусловно, фольклор как особый вид искусства представляет собой своеобразный компонент художественной культуры и является первоосновой музыкальной культуры общества. Формирование профессионального музыкального искусства Бурятии происходило в первой половине ХХ в. и создавалось на основе синтеза двух культур - национальной, фольклорной и европейской, классической. Именно на основе народной музыки возникли практически все национальные профессиональные школы, каждая из которых содержит образцы различного использования фольклорного наследия - от простейших обработок народных мелодий до индивидуального творчества, свободно претворяющего фольклорное музыкальное мышление, законы, специфические для той или иной народной музыкальной традиции.

За свою историю бурятская национальная композиторская школа прошла большой путь от первых творческих опытов молодых композиторов-бурят (1930-е гг.) до овладения основными жанрами современной музыки. В области профессионального музыкального образования отмечается переходом от устной трансляция традиции музыкального фольклора к классическому (европейскому) типу образования, в становлении которого большую роль сыграли русские музыканты, приглашенные из ведущих учебных заведений страны.

Музыкальный фольклор бурят во всех его жанрах (улигерах, песнях, инструментальных наигрышах) занимал важное место в духовной жизни бурят. Он создавался в процессе исторического развития на основе уклада жизни бурят, их хозяйственной деятельности и религиозных верований. В традиционной музыке преобладает сольное исполнительство, часто с инструментальным сопровождением, также распространены и хоровые танцевальные композиции. Бурятской музыкальной культуре свойственны локальные различия соответственно географическим и этническим зонам.

Традиции устного народного творчества бурят освещены в работах М.И. Тулохонова, А.И. Уланова, Г.Д. Фроловой, Н.О. Шаракшиновой, С.Ш. Чагдурова и др. Изучению традиции бурятской музыкальной культуры посвящены работы Д.С. Дугарова, Б.В. Олзоева, Л.Д. Дашиевой и др. 
Народное музыкальное творчество бурят состоит из нескольких жанров: музыкально-поэтический эпос - улигеры, народные песни и инструментальная музыка. Одним из ярких образцов народно-песенного творчества бурят являются улигеры. Улигеры возникли в глубокой древности и представляют собой крупные эпические поэмы в стихах. «Сказ бурятских эпических повествований - это сольный речитатив, который строится в основном на короткой попевке, равной одной строке стихотворного текста. При многократном повторе ее он варьируется. Каждый улигершин поет обычно свой излюбленный мотив, но все эти мотивы ритмичны и мелодически родственны» [2. С. 253].

В улигерах воплотились богатые художественные традиции, сложились типичные сюжеты с особым образным строем, отображающим древние мифологические воззрения бурят. К памятникам бурятского фольклорного наследия относятся такие улигеры, как «Аламжи мэргэн», «Хараасгай мэргэн», «Еренсей», «Шоно батор» и др. Среди них крупнейшим эпическим произведением бурят является «Гэсэр», распространенный у многих народов Центральной Азии и за свою масштабность получивший название «Илиада Центральной Азии». Н.О. Шаракшинова отмечает, что бурятская версия создана в общеэпическом плане бурят и отличается от версий «Гэсэра» других народов прежде всего своими размерами, доходящими до 20-30 тысяч стихотворных строк, наличием циклизации, повсеместным географическим распространением [3. С. 64]. Л.Д. Дашиева в работе «Традиционная музыкальная культура бурят» пишет, что исполнение и слушание улигеров входило в систему обязательных охотничьих обрядов. Помимо обрядовой, улигеры выполняли эстетическую и нравственно-воспитательную функции [4. С. 79-80].

Песенный фольклор с глубокой древности был тесно связан с жизнедеятельностью бурят, часто сопровождал различные культовые и семейнобытовые обряды. Песенное творчество бурят представляет собой песни различных жанров и стилей в его локальных проявлениях. В исследовании стиля бурятских народных песен большое значение имеет проблема жанровой квалификации. Исследователи выделяют несколько жанров - исторические, трудовые, свадебные, хороводные, лирические, обрядовые песни, а также древние игры и танцы, связанные с обрядами и календарными праздниками. Песни разделены не только по территориально-географическому признаку, но и по временным разделам: древние напевы, дореволюционные и советские.

Проблема классификации бурятских народных песен остается актуальной и сегодня. Благодаря накопленному песенному материалу музыкальный фольклор бурят становится предметом пристального изучения музыковедов, этномузыкологов, фольклористов, педагогов и занимает достойное место в процессе музыкального воспитания и образования подрастающего поколения.

Инструментальный фольклор также является важнейшей частью духовной культуры бурятского народа и тесно связан с религиозными и художественными представлениями, историей, особенностями быта. Описания музыкальных инструментов, в том числе буддийских культовых, освещены в работах Ю. Банеева, М.Ц. Гончиковой, Л.Д. Дашиевой, А.Г. Демина, В.В. Китова, А.М. Позднеева, Б.Ф. Смирнова и др. 
В состав бурятских народных инструментов включают культовые буддийские музыкальные инструменты, но в рамках данной работы рассмотрим традиционные народные инструменты.

Бурятские традиционные народные музыкальные инструменты в зависимости от способа звукоизвлечения входят в одну из двух групп: духовые и струнные.

К группе духовых инструментов относятся суур и лимба (это деревянные духовые инструменты). Группу струнных инструментов представляет струнносмычковый инструмент - хуур, который имел несколько разновидностей: бортого(н) хуур (хур, изготовленный из деревянного ведра, бадьи), сууха хуур (хур, изготовленный из мочевого пузыря), шанага(н) хуур (хур, изготовленный из ковша, поварёшки или «Ёдого»), хилгааһан хуур («волосяной» хур) и др. Модификация современного хура была связана с организацией оркестра бурятских народных инструментов в период проведения I декады бурят-монгольского искусства в Москве (1940 г.). В результате усовершенствования хура инструмент приобрел иную форму и своеобразное звучание. Существует несколько оркестровых разновидностей современного хура: сопрано, альт, тенор, бас и контрабас.

Следует назвать еще такие инструменты, как аман хуур («губной варган») и хэсэ (бубен), которые являлись неизменной принадлежностью бурятских шаманов.

Таким образом, бурятская народная музыка представляет собой богатый и разнообразный материал - это улигеры, песни и инструментальные наигрыши; на развитие традиций народной музыки бурят повлияли две культуры - западная (христианская) и восточная (буддийская); для нее характерны такие особенности, как сольное исполнительство, хороводные композиции, локальность исполнения; развитие традиции бурятской народной музыки в последующем трансформировались в профессиональную музыкальную культуру и образование в первой половине XX в.

В настоящее время в учебные программы образовательных учреждений музыкального образования Республики Бурятия включены дисциплины, изучающие традиционную культуру народов Бурятии, в числе которых: «Музыкальная культура Бурятии», «Музыкальный фольклор», «Народные музыкальные инструменты», «Бурятская народная музыка».

\section{Лuтература}

1. Культура и культурология : словарь / сост. А.И. Кравченко. Москва: Академ. Проект; Екатеринбург : Деловая книга, 2003. 928 с.

2. Очерки истории культуры Бурятии : в 2 т. Улан-Удэ, 1972. Т. 1. 490 с.

3. Шаракшинова Н.О. О героико-эпическом сказании бурят // Гэсэриада : прошлое и настоящее : сб. ст. и материалов о бурятском народном улигере (эпосе) / сост. Ю.И. Будаев, Б.С. Дугаров. Улан-Удэ : Бурятское отделение ВФК, 1990.

4. Дашиева Л.Д. Традиционная музыкальная культура бурят : учеб.-метод. пособие. УланУдэ : Изд. ОАО «Республиканская типография», 2005. 187 с.

Gonchikova Medegma T. Buryat State University (Ulan-Ude, Russian Federation).

E-mail: medegmag@mail.ru DOI: $10.17223 / 22220836 / 21 / 10$

TRADITIONS OF THE BURYAT FOLK MUSIC AS THE BASIS OF FORMATION OF PROFESSIONAL MUSICAL CULTURAL AND EDUCATION IN BURYATIA

Key words: musical culture, education, traditions, folklore. 
The article considers genre features of musical folklore of Buryat, which formed the basis of professional musical culture and education: musical and poetic epos (aligeri), folk songs and instrumental music. This material gives an idea of the traditional picture of the world, the specifics of folk music of the Buryats, the historical ethnic territory of the Buryat system of local folk music traditions.

Relevance of the considered problem is determined by the regional factor that the preservation, enhancement and restoration of cultural and artistic traditions of Buryatia, formed during the long historical period. The increased interest in folk art brought to life research related to collecting folk music and instrumentation. Accumulation of these data will allow more active work on the revival of Buryat folk music traditions, their further development and use in educational process. Currently, the training program of the Republic of Buryatia musical education institutions included discipline, studying the traditional culture of the peoples of Buryatia, including "Musical culture of Buryatia", "Folk music", "Folk musical instruments", "Buryat folk music."

\section{References}

1. Kravchenko, A.I. (ed.) (2003) Kul'tura i kul'turologiya [Culture and cultural studies]. Moscow: Akadem. Proekt; Ekaterinburg: Delovaya kniga.

2. Sanzhiev, G. (ed.) (1972) Ocherki istorii kul'tury Buryatii: v 2 t. [Essays on the history of Buryatia culture: In 2 vols]. Vol. 1. Ulan-Ude: Buratiya Book Publ.

3. Sharakshinova, N.O. (1990) O geroiko-epicheskom skazanii buryat [About the heroic epics of Buryats]. In: Budaev, Yu.I. \& Dugarov, B.S. (eds) Geseriada: proshloe i nastoyashchee: sb. st. i materialov o buryatskom narodnom uligere (epose) [Geseriada: Past and Present. Collected articles and materials about the Buryat folk uliger (epos)]. Ulan-Ude: VFK.

4. Dashieva, L.D. (2005) Traditsionnaya muzykal'naya kul'tura buryat [Traditional musical culture of Buryats]. Ulan-Ude: Respublikanskaya tipografiya. 